\title{
Enhanced bacterial resistance in transgenic tobacco expressing a BrRZFP1 encoding a C3HC4-type RING zinc finger protein from Brassica rapa
}

\author{
Yu Jin Jung $\cdot$ Ill Sup Nou Sung Kee Hong Young Kee Lee $\cdot$ Yong Gu Cho $\cdot$ Kwon Kyoo Kang
}

Received: 16 March 2013 / Accepted: 27 March 2013

(c) Korean Society for Plant Biotechnology

\begin{abstract}
C3HC4-type RING zinc finger proteins essential in the regulation of plant processes, including responses to abiotic stresses. We previously isolated and examined the C3HC4-type RING zinc finger protein (BrRZFPl) from Brassica rapa under abiotic stresses. To elucidate the role of the BrRZFPl transcription factor in gene regulation, we transformed tobacco plants with the BrRZFPl gene. Plants were regenerated from 82 independently transformed callus lines of tobacco and analysed for transgene expression. Transgene integration and expression was confirmed by Southern and RT-PCR analyses, respectively. T2 plants displayed more tolerance to the bacterial pathogens Pectobacterium carotovorum and Ralstonia solanacearum, and the tolerance levels were correlated with BrRZFPl expression levels. These results suggest that the transcription factor BrRZFP1 is an important determinant of stress response in plants and its overexpression in plants could increase biotic stress resistance.
\end{abstract}

Keywords abiotic stress, biotic stress resistance, disease resistance, stress response, zinc finger protein

Y. J. Jung · K. K. Kang $(\bowtie)$

Department of Horticulture, Hankyong National University, Ansung, 456-749, Korea

e-mail: kykang@hknu.ac.kr

\section{S. Nou}

Department of Horticulture, Sunchon National University, Suncheon, 540-742, Korea

\section{S. K. Hong}

Planning \& Coordination Division, National Academy of Agricultural Science, Suweon, 441-707, Korea

\section{Y. K. Lee}

Crop Protection Division National Academy of Agricultural Science, Suweon, 441-707, Korea

\section{Y. G. Cho $(\bowtie)$}

Department of Crop Science, Chungbuk National University, Cheongju, 361-763, Korea

e-mail: ygcho@cbnu.ac.kr

\section{Introduction}

Zinc finger proteins are a superfamily involved in many aspects of plant growth and development. They have been classified into nine types according to their structural and functional diversities: $\mathrm{C} 2 \mathrm{H} 2, \mathrm{C} 8, \mathrm{C} 6, \mathrm{C} 3 \mathrm{HC} 4, \mathrm{C} 2 \mathrm{HC}$, $\mathrm{C} 2 \mathrm{HC} 5, \mathrm{C} 4, \mathrm{C} 4 \mathrm{HC} 3$ and $\mathrm{CCCH}$ (C and $\mathrm{H}$ represent cysteine and histidine, respectively) (Berg \& Shi 1996; Takatsuji 1998; Moore \& Ullman 2003; Jenkins et al. 2005; Schumann et al. 2007). Many zinc finger proteins have been confirmed to be involved in abiotic and biotic stresses (Sakamoto et al. 2004; Ham et al. 2006; Oh et al. 2006; Ciftci-Yilmaz et al. 2007).

The RING (Really Interesting New Genes) finger was defined as a novel zinc finger domain (Freemont et al. 1991) which has been found in proteins involved in various signal transduction pathways and regulatory pathways (Saurin et al. 1996; Vij and Tyagi 2006). Among the RING finger domains, C3HC4-type is a cysteine-rich domain of 40-60 residues that coordinates two zinc ions (Haas et al. 2002; Alexandrov et al. 2006). C3HC4-type RING finger genes comprise a large family in the plant kingdom and play important roles in various physiological processes of plant life. C3HC4-type RING finger proteins have been studied on a genomic scale in Arabidopsis (Stone et al. 2005). Arabidopsis RING-HC proteins with predicted or known biological functions include AtTED3 (light signaling) (Pepper and Chory 1997), AtRMAl (secretory pathway) (Matsuda et al. 2001), AtXB3 (root development) (Wang et al. 2006), AtHUB1 and AtHUB2 (chromatin modifications) (Liu et al. 2007), and AtSDIRl (stress tolerance) (Zhang et al. 2007). The $\mathrm{C} 2 \mathrm{H} 2$-type zinc finger protein $\mathrm{Z}$ at 12 (responsive to high light zinc finger protein 12 of Arabidopsis thaliana) plays a central role in reactive oxygen and abiotic stress signaling in Arabidopsis (Davletova et al. 2005).

The C3HC4-type RING finger proteins have been studied on a genomic scale in Arabidopsis, and nucleotide sequences 
from ends of several BAC clones of Brassica rapa are similar to Arabidopsis genomic sequences, yet there has been no examination of these genes in B. rapa (Ma et al. 2009). In this study, we transformed tobacco plants to overexpress C3HC4-type RING zinc finger protein (BrRZFP1), which is derived from $B$. rapa (Chinese cabbage or 'Baechu' in Korea), and assayed the level of resistance to pathogen attack in the transgenic tobacco plants.

\section{Materials and Methods}

Plant material

Tobacco seeds (Nicotiana tabacum cv. NC89) were obtained from the National Horticultural Research Institute (RDA, Suwon, Korea). The seeds were surface-sterilized in $1 \%$ $(\mathrm{v} / \mathrm{v}) \mathrm{NaOCl}$ at room temperature for $10 \mathrm{~min}$, followed by three times rinse with sterilized distilled water for $5 \mathrm{~min}$. Seeds were then germinated on MS agar medium (Murashige and Skoog 1962) and kept in a plant growth chamber under a $16 \mathrm{~h}$ photoperiod at $25^{\circ} \mathrm{C}$ for 2 weeks.

\section{Tobacco transformation}

The full-length C3HC4-type RING zinc finger protein $(B r R Z F P l)$ gene was amplified from the pGEM-T easy vector containing $B r R Z F P 1$ with the primers $B r R Z F P 1$-F1 $\left(5^{\prime}\right.$-ATGCCTTCTTCTGGAGATCCC-3') and BrRZFPl-R1 ( $5^{\prime}$-TTAAACAAATGGCATAGTTTTAC-3'). The identity was confirmed by sequencing, after which it was inserted into the BamHI and KpnI sites of the pBI121 plant binary vector system for overexpression under the control of a modified cauliflower mosaic virus (CaMV) 35S promoter. The pBigs plant binary vector containing complete coding sequence of $B r R Z F P 1$ was introduced into tobacco seedlings via Agrobacterium tumefaciens-mediated transformation according to the procedure of Horsch et al. (1985).

PCR analysis of transgenic tobacco plants

Four week old tobacco seedlings were analysed using PCR amplification to select transgenic lines. DNA was extracted from the leaves of the tobacco seedlings using the cetyltrimethyl ammonium bromide (CTAB) method (Rogers \& Bendich 1994). The primer set for the PCR amplification and the probe for the Southern blot analysis were BrRZFP1-F2 and BrRZFP1-R2. The PCR amplification profile consisted of an initial step at $94^{\circ} \mathrm{C}$ for $5 \mathrm{~min}$ followed by 30 cycles of $94^{\circ} \mathrm{C}$ for $1 \mathrm{~min}, 58^{\circ} \mathrm{C}$ for $1 \mathrm{~min}$, $72^{\circ} \mathrm{C}$ for $2 \mathrm{~min}$, and a final step at $72^{\circ} \mathrm{C}$ for $10 \mathrm{~min}$.

RNA isolation and Real-time PCR

Total RNA from leaf tissue was extracted using Trizol reagent (Invitrogen, USA) according to the manufacturer's protocol. The specific primers for the analysis of $B r R Z F P 1$ expression of germinating seeds were: BrRZFP1-F3 $5^{\prime}$ ATGCCTTCTTCTGGAGATCC-3' and BrRZFP1-R3 5'GTTCGTTGGACGATGAAGGT-3'. Real-time PCR was performed using a Bio-RAD I Cycler IQ5 machine as previously described using RT pre-mix (TOYOBO Co., Japan) (Ali-Benali et al. 2005). The threshold cycle (Ct) values of PCR reactions from three independent biological replicates were averaged and the relative quantification of the expression levels was performed using the comparative $\mathrm{Ct}$ method for all experiments (Livak et al. 2001). The fold change in total RNA of a target gene relative to the reference gene (actin gene) was determined by the following formula: fold change $=2^{-\Delta \Delta \mathrm{Ct}}$, where $\Delta \Delta \mathrm{Ct}=(\mathrm{Ct}$ target gene $\mathrm{Ct}$ actin gene) transgenic plants - $(\mathrm{Ct}$ target gene $-\mathrm{Ct}$ actin gene $)$ wild-type plants.

\section{Pathogen tolerance assay}

The bacterial pathogens of Pectobacterium carotovorum subsp. carotovorum and Ralstonia solanacearum were provided and identified by the National Horticultural Research Institute (RDA, Suwon, Korea). Cultures of $P$. carotovorum subsp. carotovorum and $R$. solanacearum were incubated in YEP medium at $30^{\circ} \mathrm{C}$. After being adjusted to optical density (at $600 \mathrm{~nm}$ ) $0.01,0.1 \%$ Silwet was added to the bacterial suspension, where transgenic tobacco plants were dip inoculated, as described by Zoubenko et al. (1997). The inoculated plants were transferred to a growth chamber and incubated at $28^{\circ} \mathrm{C}$ under continuous light. For the bacterial growth count, $0.5 \mathrm{~cm}$ leaf disks were ground with $1 \mathrm{ml}$ of $10 \mathrm{mM} \mathrm{MgCl} 2$ solution and layered onto selective medium in $9 \mathrm{~cm}$ Petri dishes. The number of colony-forming units (cfu) was counted after 4 days of growth. In vivo screenings were monitored in 3, 5 and 8 days after inoculation for Pectobacterium carotovorum subsp. carotovorum and in 7, 14, and 21 days for Ralstonia solanacearum. Disease symptom was scored using the disease rating scales as follows: +1 , highly susceptible; + , moderately susceptible; + , susceptible: and - , resistance. 


\section{Results}

Analysis of the $35 \mathrm{~S}::$ BrRZFP1 plants

Tobacco plants (Nicotiana tabacum cv. NC89) were successfully transformed to express the BrRZFPl gene under the control of a cauliflower mosaic virus $35 \mathrm{~S}$ promoter. Figure 1A describes the vector structure. A total of 33 regenerated calli were recovered from the shoot regenerating medium, and then transferred to shoot elongation and rooting medium. The $\mathrm{T} 1$ seeds were harvested after 8-10 weeks, and rooting transgenic plants were acclimated in pots containing sterilized soil. The transgenic T2 and T3 progeny plants did not show any obvious differences in growth and development with the wild-type plants, and control plants transformed with empty vector (Fig. 1B). The presence of the BrRZFPl gene in the transgenic tobacco plant genomes was confirmed by PCR for the NPTII and BrRZFP1 sequences. All of the tested lines showed the expected $0.7 \mathrm{~kb}$ band of NPTII and $1.2 \mathrm{~kb}$ band of $B r R Z F P 1$, implicating the successful transformation of the $B r R Z F P 1$ gene into the tobacco genome (Fig. 2A). The expression level of the BrRZFP1 transcript in the transgenic plants was analyzed by RT-PCR analysis (Fig. 2B). Although all of the transgenic lines expressed the BrRZFP1 gene, the level of expression varied among the lines. Among the ten independent transgenic lines, the expression level was highest in five lines $(1,12,13,19$ and 39) and lowest in three lines (24, 26 and 31) (Fig. 2C).
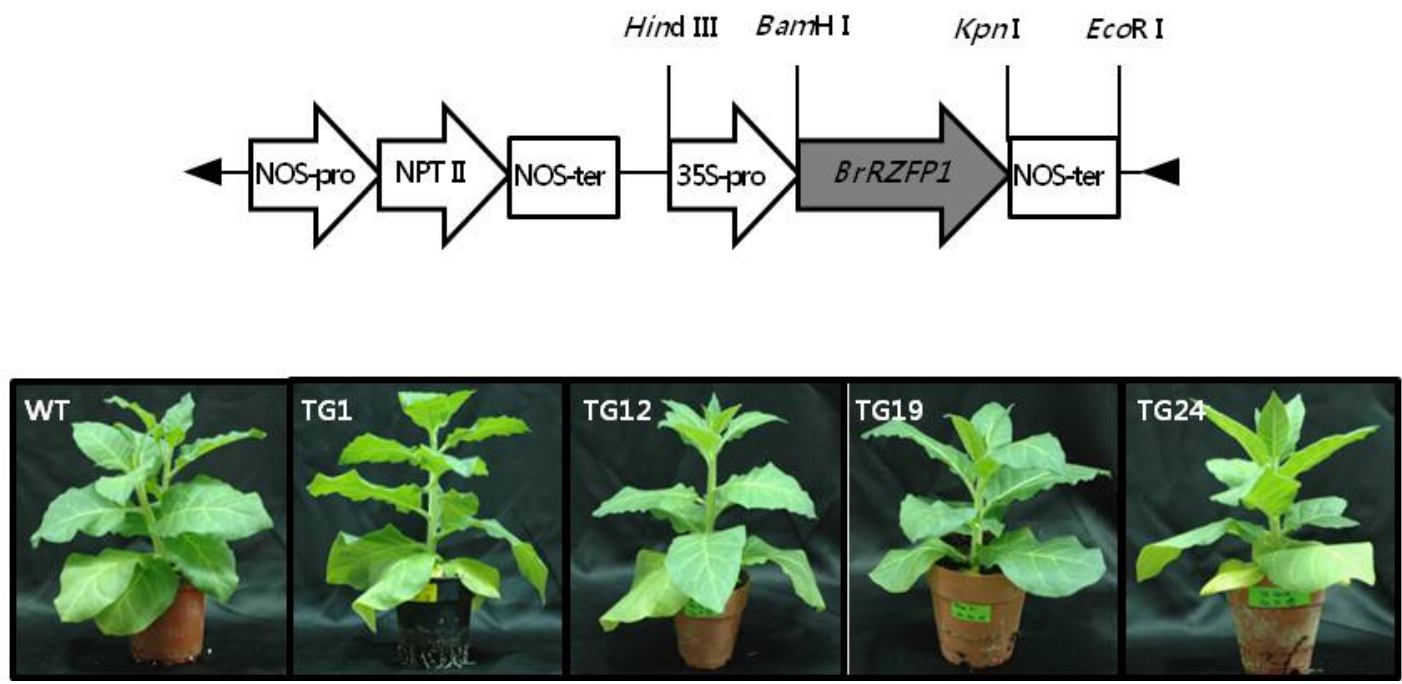

Fig. 1 Construction of the plant expression vector and generation of transgenic plants. (A) Diagram of the full-length $B r R Z F P 1$ cDNA cloned into the plant gene expression vector $p B I 121$. (B) T2 progenies grown in soil. Seeds of wild-type (WT) and transgenic lines were planted in soil contained in a pot and grown for seed production. Photos were taken during the fruit development stage.

A)

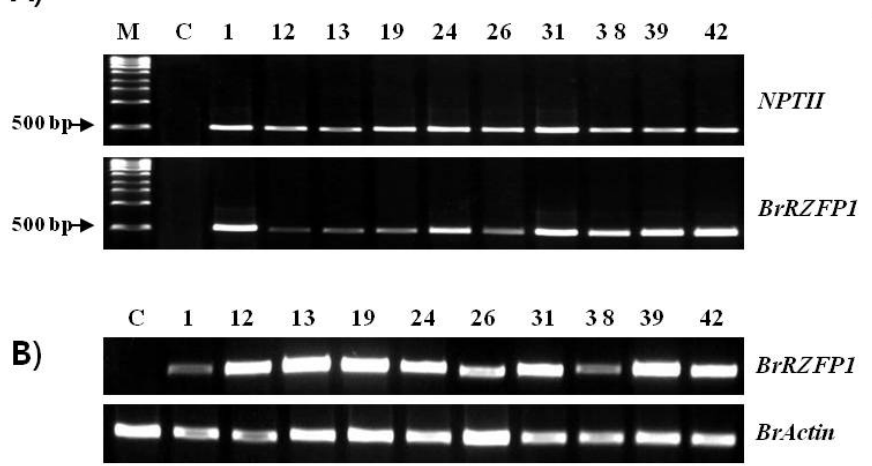

C)

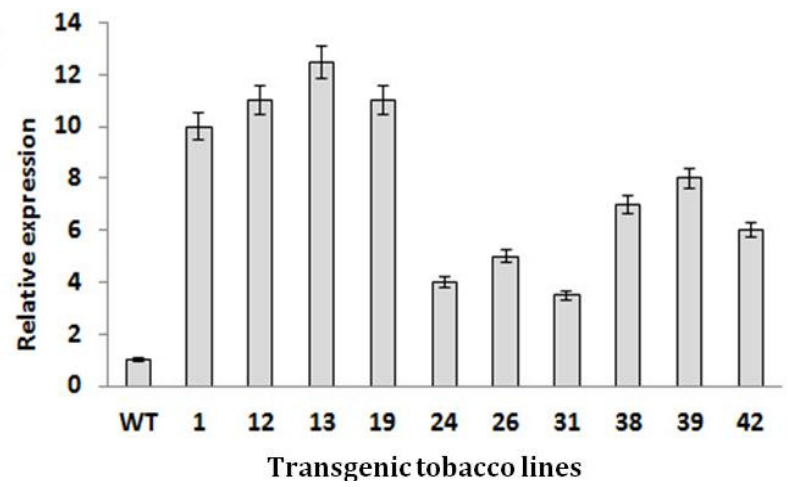

Fig. 2 PCR, RT-PCR and realtime PCR analyses of transgenic tobacco plants. (A) PCR analyses were performed on transgenic T0 tobacco plants, using NPTII and BrRZFPl gene-specific primers. M, 1 kb DNA ladder (Invitrogen, San Diego, CA); C, Control plants; Nos. 1-42, 10 independent transgenic lines. (B) RT-PCR analysis of T1 progeny, (C) BrRZFP1 messenger RNA expression in transgenic T2 tobacco plants. Ten independent transgenic lines and a control plant were subjected to realtime PCR analysis. Total RNA was extracted from fully expanded leaves of 5-week-old tobacco plants. Vertical bars indicate standard deviation $(n=3)$ 
A)

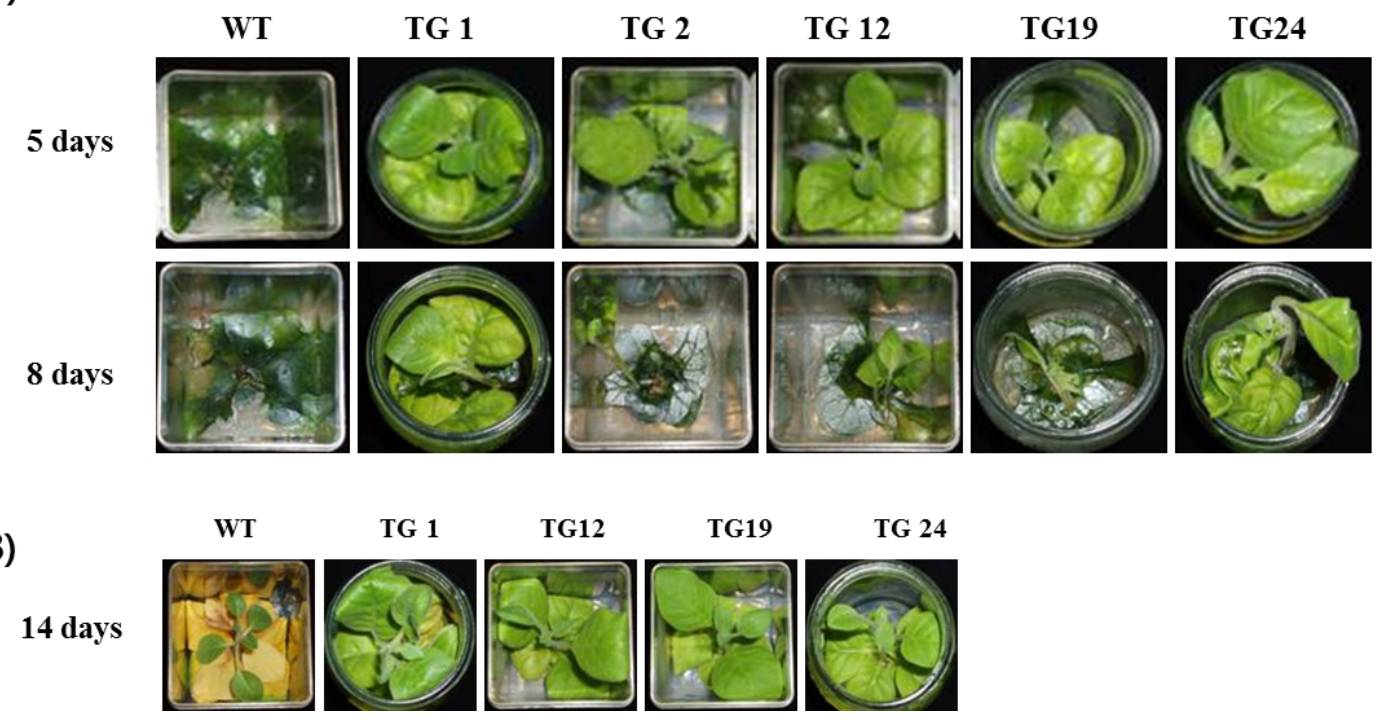

Fig. 3 Temporal development of soft rot in transgenic tobacco plants when the leaves were inoculated with Pectobacterium carotovorum subsp. carotovorum (A) and Ralstonia solanacearum (B). WT: wild type, TG1-TG24: transgenic homozygous lines

Table 1 Response of transgenic tobacco plants with BrRZFP1 against Pectobacterium carotovorum subsp. carotovorum

\begin{tabular}{llccc}
\hline \multirow{2}{*}{ Bacterial strain } & Type of plant & \multicolumn{3}{c}{ Days after infection } \\
\cline { 3 - 5 } & Wild type & +++ & +++ & +++ \\
& TG 1 & - & + & ++ \\
\multirow{2}{*}{$\begin{array}{l}\text { Pectobacterium } \\
\text { carotovorum subsp. }\end{array}$} & TG 2 & + & ++ & +++ \\
carotovorum & TG 12 & ++ & ++ & +++ \\
& TG 19 & + & + & +++ \\
& TG 24 & - & + & ++ \\
\hline
\end{tabular}

Disease symptom was determined by disc assay as described by Zoubenko et al. (1997). Disease symptom was scored using the disease rating scales as follows: +++ , highly susceptible; ++ , moderately susceptible; + , susceptible: and -, resistance.

Enhanced resistance to $P$. carotovorum subsp. carotovorum and $R$. solanacearum

To examine whether the transgenic plants have enhanced resistance to bacterial pathogens, we inoculated the wild type and transgenic plants with $P$. carotovorum subsp. carotovorum and $R$. solanacearum and monitored the bacterial growth. In case of $P$. carotovorum subsp. carotovorum, 3 days after inoculation, the control plants and transgenic plant lines showed no difference in bacterial growth. However, after 5 days two transgenic lines displayed increased resistance, with bacterial growth two-fold lower in line TG1 and eight-fold lower in line TG24 than in the wild type plants (Fig. 3A, Table 1). In case of $R$.
Table 2 Response of transgenic tobacco plants with BrRZFPI against Ralstonia solanacearum

\begin{tabular}{llllc}
\hline \multirow{2}{*}{ Bacterial strain } & Type of plant & \multicolumn{3}{c}{ Days after infection } \\
\cline { 3 - 5 } & Wild type & 7 & 14 & 21 \\
\hline \multirow{3}{*}{ Ralstonia } & TG 1 & - & ++ & +++ \\
solanacearum & TG 12 & - & + & ++ \\
& TG 19 & - & + & ++ \\
& TG 24 & - & - & + \\
\hline
\end{tabular}

Disease symptom was determined by disc assay as described by Zoubenko et al. (1997). Disease symptom was scored using the disease rating scales as follows: +++, highly susceptible; ++, moderately susceptible; +, susceptible: and -, resistance.

solanacearum, 7 days after inoculation, the control plants and transgenic plants showed no difference in bacterial growth. However, after 14 days two transgenic lines displayed increased resistance, with bacterial growth two-fold lower in line TG19 and eight-fold lower in line TG24 than in the wild type plants (Fig. 3B, Table 2). Disease symptoms correlated with bacterial growth, where leaves of the wild type tobacco plants exhibited severe chlorosis, which is significantly reduced in the transgenic plants (data not shown). Transgenic lines exhibited a delay in the appearance of disease symptoms and a significantly lower mortality rate compared with controls. These results demonstrated that the enhanced resistance to $P$. carotovorum subsp. carotovorum and $R$. solanacearum may be conferred by BrRZFP1 overexpression in transgenic plants. 


\section{Discussion}

Transcription factors have been shown to play important roles in signal transduction and gene expression under plant stress responses to salt, cold and drought (Chen et al. 2002; Shinozaki et al. 2003; Bartels \& Sunkar 2005; Yang et al. 2008). A better understanding of stress-regulated transcription factors through cloning and characterization will be highly valuable in improving plant stress tolerance (Wang et al. 2003). The C3HC4-type RING zinc finger proteins play important roles in a variety of plant processes, including regulation of growth and development, protein-protein interactions and signaling networks (Freemont 1993; Borden et al. 1995; Tsuge et al. 2001; Wang et al. 2006). In addition, these transcription factors have been linked to abiotic stress processes for cold and salt (Lee et al. 2001; Xiong et al. 2002; Mukhopadhyay et al. 2004; Huang et al. 2011). Importantly, several studies have also linked RING domain containing proteins to E3 ubiquitin ligase activity and these same abiotic stress-regulated processes (Lyzenga \& Stone 2012), e.g. zinc finger proteins such as ZFP1 from Artemisia desertorum (Yang et al. 2008).

Our cloned BrRZFPl gene encodes the C3HC4-type RING zinc finger transcription factor, which is a nucleartargeting protein and functions as a transcription regulator (Jung et al. 2013). Here, we showed that transgenic tobacco plants overexpressing BrRZFPl exhibited enhanced resistance to the bacterial pathogens $P$. carotovorum subsp. carotovorum and $R$. solanacearum, thus demonstrating the important role of BrRZFPl in plant defense. Combined with our previous report of enhanced tolerance to bacterial pathogens of transgenic tobacco by overexpressing BrRZFPl, our new finding of enhanced disease tolerance of transgenic tobacco plants adds substance to the idea that BrRZFPI may play a similar role in the defense response of all Solanaceous species. Although we do not have an overall understanding of gene regulation by $B r R Z F P 1$, our data on massive change of BrRZFP1 expression levels may enable us to identify the essential genes for these protective actions. We plan to identify the target genes directly regulated by $B r R Z F P 1$ and its promoter sequences, characterize the associated trans-acting factors and eventually develop multiple stress-resistant plants using the knowledge gained.

\section{Acknowledgement}

This work was supported by the research grant of the Chungbuk National University in 2011.

\section{References}

Alexandrov NN, Troukhan ME, Brover VV, Tatarinova T, Flavell RB, Feldmann KA (2006) Features of Arabidopsis gene and genome discovered using full-length cDNAs. Plant Mol Biol 60:71-87

Ali-Benali MA, Alary R, Joudrier P, Gautier M (2005) Comparative expression of five LEA genes during wheat seed development and in response to abiotic stresses by real-time quantitative RT-PCR. Biochimica et Biophysica Acta 1730: 56-65

Bartels D, Sunkar R (2005) Drought and salt tolerance in plants. Critical Reviews in Plant Sciences 24:23-58

Berg JM, Shi Y (1996) The galvanization of biology: a growing appreciation for the roles of zinc. Science 271:1081-1085

Borden KL, Boddy MN, Lally J, O'Reilly NJ, Martin S, Howe K, Solomon E, Freemont PS (1995) The solution structure of the RING finger domain from the acute promyelocytic leukaemia proto-oncoprotein PML. The EMBO Journal 14:1532-1541

Chen W, Provart NJ, Glazebrook J, et al. (2002) Expression profile matrix of Arabidopsis transcription factor genes suggests their putative functions in response to environmental stress. The Plant Cell 14:559-574

Ciftci-Yilmaz S, Morsy MR, Song L, Coutu A, Krizek BA, Lewis MW, Warren D, Cushman J, Connolly EL, Mittler R (2007) The EAR-motif of the Cys2/His2-type zinc finger protein Zat7 plays a key role in the defense response of Arabidopsis to salinity stress. Journal of Biological Chemistry 282:9260-9268

Cong L, Chai TY, Zhang YX (2008) Characterization of the novel gene BjDREB1B encoding a DRE-binding transcription factor from Brassica juncea L. Biochemical and Biophysical Research Communications 371:702-706

Davletova S, Schlauch K, Coutu J, Mittler R (2005) The zinc-finger protein Zat12 plays a central role in reactive oxygen and abiotic stress signaling in Arabidopsis. Plant Physiology 139:847-856

Freemont PS, Hanson IM, Trowsdale J (1991) A novel cysteinerich sequence motif. Cell 64:483-484

Freemont PS (1993) The RING finger: a novel protein sequence motif related to the zinc finger. Annals of the New York Academy of Sciences 684:174-192

Golldack D, Lüking I, Yang O (2011) Plant tolerance to drought and salinity: stress regulating transcription factors and their functional significance in the cellular transcriptional network. Plant Cell Rep 30:1383-1391

Ham BK, Park JM, Lee SB, Kim MJ, Lee IJ, Kim KJ, Kwon CS, Paek KH (2006) Tobacco Tsip1, a DnaJ-type Zn finger protein, is recruited to and potentiates Tsi1-mediated transcriptional activation. The Plant Cell 18:2005-2020

Haas BJ, Volfovsky N, Town CD, Troukhan M, Alexandrov N, Feldmann KA, Flavell RB, White O, Salzberg SL (2002) Full-length messenger RNA sequences greatly improve genome annotation. Genome Biol 3:1-12

Horsch RB, Fry JE, Hoffmann N, Wallroth M, Eichholtz D, Rogers SG, Fraley RT (1985) Science 227:1229-1231 
Huang D, Wu W, Abrams SR, Cutler AJ (2008) The relationship of drought-related gene expression in Arabidopsis thaliana to hormonal and environmental factors. Journal of Experimental Botany 59:2991-3007

Jenkins TH, Li J, Scutt CP, Gilmartin PM (2005) Analysis of members of the Silene latifolia Cys2/His2 zinc-finger transcription factor family during dioecious flower development and in a novel stamen-defective mutant ssf1. Planta 220: 559-571

Jung YJ, Lee IH, Nou IS, Lee KD, Rashotte AM, Kang KK (2013) BrRZFP1 a Brassica rapa C3HC4-type RING zinc finger protein involved in cold, salt, and dehydration stress. Plant Biology 15:274-283

Kwon SI, Koczan JM, Gassmann W (2004) Two Arabidopsis srfr (suppressor of rps4-RLD) mutants exhibit avrRps4-specific disease resistance independent of RPS4. Plant J 40:366-375

Lee H, Xiong L, Gong Z, Ishitani M, Stevenson B, Zhu JK (2001) The Arabidopsis HOS1 gene negatively regulates cold signal transduction and encodes a RING finger protein that displays cold-regulated nucleo-cytoplasmic partitioning. Genes \& Development 15:912-924

Liu, Y., Koornneef, M., Soppe,W.J. (2007) The absence of histone H2B monoubiquitination in the Arabidopsis hub1 (rdo4) mutant reveals a role for chromatin remodeling in seed dormancy. Plant Cell 19, 433-444

Livak KJ, Schmittgen TD (2001) Analysis of relative gene expression data using real-time quantitative PCR and the 2 $-\triangle \triangle \mathrm{Ct}$ method. Methods 25:402-408

Lyzenga WJ, Stone SL (2012) Abiotic stress tolerance mediated by protein ubiquitination. J Exp Bot63:599-616

Ma K., Xiao J., Li X., Zhang Q., Lian X. (2009) Sequence and expression analysis of the C3HC4-type RING finger gene family in rice. Gene 444:33-45

Matsuda, N., Suzuki, T., Tanaka, K., Nakano, A. (2001) Rma1, a novel type of RING finger protein conserved from Arabidopsis to human, is a membrane-bound ubiquitin ligase. J. Cell Sci. 114: $1949-1957$

Moore M, Ullman C (2003) Recent developments in the engineering of zinc finger proteins. Briefings in Functional Genomics and Proteomics 1:342-355

Mukhopadhyay A, Vij S, Tyagi AK (2004) Overexpression of a zinc-finger protein gene from rice confers tolerance to cold, dehydration, and salt stress in transgenic tobacco. Proceedings of the National Academy of Sciences 101:6309-6314

Murashige T, Skoog F (1962) A revised medium for rapid growth and bio assays with tobacco tissue cultures. Physiologia Plantarum 15:473-497

Oh SK, Yi SY, Yu SH, Moon JS, Park JM, Choi D (2006) CaWRKY2, a chili pepper transcription factor, is rapidly induced by incompatible plant pathogens. Molecular Cell 22:58-64

Pepper, A.E., Chory, J. (1997) Extragenic suppressors of the Arabidopsis det 1 mutant identify elements of flowering-time and light-response regulatory pathways. Genetics 145, 1125-1137

Rogers SR, Bendich AJ (1994) Extraction of total cellular DNA from plants, algae and fungi; In: Gelvin SB and Schilperoort RA (eds). Plant Molecular Biology Manual (Dordrecht, The
Netherlands: Kluwer Academic Publishers) $2^{\text {nd }}$ edition:1-8

Sakamoto H, Maruyama K, Sakuma Y, Meshi T, Iwabuchi M, Shinozaki K, Yamaguchi-Shinozaki K (2004) Arabidopsis Cys2/His2-type zinc-finger proteins function as transcription repressors under drought, cold, and high-salinity stress conditions. Plant Physiology 136:2734-2746

Saurin AJ, Borden KLB, Boddy MN, Freemont PS (1996) Does this have a familiar RING? Trends Biochem Sci 21:208-214

Schumann U, Prestele J, O'Geen H, Brueggeman R, Wanner G, Gietl C (2007) Requirement of the C3HC4 zinc RING finger of the Arabidopsis PEX10 for photorespiration and leaf peroxisome contact with chloroplasts. Proceedings of the National Academy of Sciences, USA 104:1069-1074

Shinozaki K, Yamaguchi-Shinozaki K, Seki M (2003) Regulatory network of gene expression in the drought and cold stress responses. Current Opinions in Plant Biology 6:410-417

Stone, S.L., Hauksdottir, H., Troy, A., Herschleb, J., Kraft, E., Callis ( 2005) Functional analysis of the RING-type ubiquitin ligase family of Arabidopsis. Plant Physiol. 137, 13-30

Takatsuji H (1998) Zinc-finger transcription factors in plants. Cell Mol Life Sci 54:582-596

Tran LS, Nakashima K, Shinozaki K, Yamaguchi-Shinozaki K (2007) Plant gene networks in osmotic stress response: from genes to regulatory networks. Methods in Enzymology 428: 109-128

Tsuge T, Inagaki N, Yoshizumi T, Shimada H, Kawamoto T, Matsuki R, Yamamoto N, Matsui M (2001) Phytochromemediated control of COP1 gene expression in rice plants. Molecular Genetics \& Genomics 265:43-50

Vij S, Tyagi AK (2006) Genome-wide analysis of the associated protein (SAP) gene family containing A20/AN1 zinc-finger(s) in rice and their phylogenetic relationship with Arabidopsis. Mol Gen Genomics 276:171-565

Wang YS, Pi LY, Chen X, Chakrabarty PK, Jiang J, De Leon AL, Liu GZ, Li L, Benny U, Oard J, Ronald PC, Song WY (2006) Rice XA21 binding protein 3 is a ubiquitin ligase required for full Xa21-mediated disease resistance. The Plant Cell 18: 3635-3646

Wang W, Vinocur B, Altman A (2003) Plant responses to drought, salinity and extreme temperatures: towards genetic engineering for stress tolerance. Planta 218:1-14

Xiong L, Schumaker KS, Zhu JK (2002) Cell signaling during cold, drought, and salt stress. The Plant Cell 14:165-183

Yang X, Sun C, Hu Y, Zhongping L (2008) Molecular cloning and characterization of a gene encoding RING zinc finger ankyrin protein from drought-tolerant Artemisia desertorum. Journal of Bioscience 33:103-112

Zhang, Y., et al. (2007) SDIR1 is a RING finger E3 ligase that positively regulates stress responsive abscisic acid signaling in Arabidopsis. Plant Cell 19, 1912-1929

Zheng X, Chen B, Han B (2009) Overexpression of a NAC transcription factor enhances rice drought and salt tolerance. Biochemical and Biophysical Research Communications 379:985-989

Zoubenko O, Uckun F, Hur Y, Chet I, Tumer N (1997) Plant resistance to fungal infection induced by nontoxic pokeweed antiviral protein mutants. Nature Biotechnology 15:992-996 